\title{
AS JUSTIFICATIVAS MORAIS DO "ESPÍRITO" DO CAPITALISMO A PARTIR DE CONCEPÇÃO DE PROFISSÃO E REGIMENTO ASCÉTICO DA CONDUTA DE VIDA
}

\author{
LAS JUSTIFICATIVAS MORAIS DEL “ESPÍRITU” DEL CAPITALISMO A PARTIR \\ DE CONCEPCIÓN DE PROFESIÓN Y REGIMEN ASCÉTICO DE LA CONDUCTA DE \\ VIDA
}

\begin{abstract}
THE MORAL JUSTIFICATIONS OF THE "SPIRIT" OF CAPITALISM FROM CONCEPTION OF PROFESSION AND ASCETIC REGIMENT OF CONDUCT OF LIFE
\end{abstract}

Pedro Dionizio de MELLO ${ }^{1}$

RESUMO: O presente artigo busca analisar, a partir da obra clássica "A Ética Protestante e o Espírito do Capitalismo", de Max Weber, como modalidades de conduta de vida e concepção de profissão foram adaptadas à peculiaridade do capitalismo ocidental moderno, erigindo as bases para a constituição de um novo ethos profissional. Trata-se, portanto, de investigar de que forma a doutrina calvinista da predestinação produziu elementos de estímulos psicológicos que fizeram com que indivíduos apresentassem ímpetos empreendedores voltados à acumulação racional de capital. Para tanto, foi feita uma revisão bibliográfica em torno de duas dimensões de análise da obra em questão: profissão como vocação e regimento ascético da conduta de vida. Ao fim e ao cabo, o estudo constatou que a educação religiosa para a ascese, reprovando o consumo e incentivando sua aplicação na produção, bem como legitimando o lucro econômico privado, implicou em efeitos significativos para o desencadeamento do capitalismo de tipo racional.

PALAVRAS-CHAVE: Espírito do capitalismo. Concepção de profissão. Conduta de vida. Weber.

RESUMEN: El presente artículo busca analizar, a partir de la obra clásica "La Ética Protestante y el Espíritu del Capitalismo", de Max Weber, como modalidades de conducta de vida y concepción de profesión, fueron adaptadas a la peculiaridad del capitalismo occidental moderno, erigiendo las bases para la constitución de un nuevo ethos profesional. Se trata, pues, de investigar de qué forma la doctrina calvinista de la predestinación produjo elementos de estímulos psicológicos que hicieron con que individuos presentaran ímpetu emprendedores volitados a la acumulación racional de capital. Para ello, se realizó una revisión bibliográfica en torno a dos dimensiones de análisis de la obra en cuestión: profesión como vocación y regimiento ascético de la conducta de vida. Al fin y al cabo, el estudio constató que la educación religiosa para la ascesis, reprobando el consumo y alentando su aplicación en la producción, así como legitimando el lucro económico privado, implicó en efectos significativos para el desencadenamiento del capitalismo de tipo racional.

${ }^{1}$ Universidade Federal do Rio Grande do Sul (Ufrgs), Porto Alegre - Rio Grande do Sul - Brasil. Mestre em Sociologia e pesquisador associado ao Grupo de Pesquisa Sociedade e Economia (GPSET/UFRGS). E-mail: p.mello.07@gmail.com. 
PALABRAS CLAVE: Espíritu del capitalismo. Concepción de profesión. Conducta de vida. Weber.

ABSTRACT: This article aims to analyze, from Max Weber's classic work "The Protestant Ethic and the Spirit of Capitalism", how the modes of life conduct and conception of profession were adapted to the peculiarity of modern Western capitalism, laying the foundations for constitution of a new professional ethos. It is therefore a question of investigating how the Calvinistic doctrine of predestination produced elements of psychological stimuli that made individuals present entrepreneurial drives aimed at the rational accumulation of capital. In order to do so, a bibliographical revision was made around two dimensions of analysis of the work in question: profession as vocation and ascetic regiment of conduct of life. After all, the study found that religious education for ascesis, failing consumption and encouraging its application in production, as well as legitimizing private economic profit, implied in significant effects for the unleashing of rational capitalism.

KEYWORDS: Spirit of Capitalism. Conception of profession. Conduct of life. Weber.

\section{Introdução}

Em meio à contribuição quase enciclopédica de Max Weber às ciências sociais, uma pergunta pode ser utilizada como fio-condutor para situar suas discussões no âmbito mais específico da Sociologia Econômica: por que somente no Ocidente emergiu aquilo que viria ser um modelo de desenvolvimento econômico predominante, o capitalismo de tipo racional?

Em linhas gerais, essa questão sintetiza os esforços empreendidos por Weber para compreender a gênese dos processos sociais singulares do Ocidente para a produção de sua riqueza material. A questão também carrega um pressuposto metodológico fundamental da sociologia weberiana: a noção de singularidade histórica, ou seja, conexões de diferentes elementos da realidade histórica (culturais, econômicos, políticos, éticos, etc.) sob condições particulares - e não necessárias ou determinadas - que vão engendrar efeitos impremeditados nas ações dos indivíduos. Afasta-se, portanto, das concepções de ciência baseadas no naturalismo metodológico. Assim, a própria tese de Weber acerca das afinidades eletivas entre desenvolvimento econômico capitalista e ética protestante é uma das diversas causas possíveis para a compreensão do seu problema de pesquisa: a emergência capitalismo de tipo racional. Implica, também, na afirmação da existência de diversos tipos singulares de capitalismo na realidade histórica e, ainda, na coexistência de distintos tipos de capitalismos em uma mesma organização econômica. 
A capacidade de adaptação do capitalismo a fatores religiosos está relacionada diretamente a uma necessidade de encaixe entre forma e conteúdo: para além das précondições objetivas que dão forma ao capitalismo racional - propriedade privada dos meios de produção, trabalho formalmente livre, contabilidade racional do capital, mercado livre de regras tradicionais, direito previsível e calculável, etc. (WEBER, 2006, p. 16-17) - sua emergência também está atrelada à internalização de disposições psicológicas nos indivíduos que não estão dadas pela natureza, mas são o produto de um longo e árduo processo educacional. Trata-se da afirmação de Weber de que "o capitalismo [...] educa e cria para si mesmo, por via da seleção econômica, os sujeitos econômicos - empresários e operários - de que necessita (2007, p. 26)".

Essas disposições mencionadas também não emergiram em indivíduos singulares isolados, mas sim como um modo de ver portado por grupos de pessoas. Dessa forma, o que se pretende aqui analisar é como modalidades de conduta de vida e concepção de profissão foram adaptadas à peculiaridade do capitalismo ocidental moderno. Em outras palavras, investigar as justificativas morais que engajaram os indivíduos dentro do "espírito" do capitalismo. Essas justificativas serão investigadas a partir de uma revisão bibliográfica das seguintes dimensões de análise: a profissão como uma vocação e o regimento ascético da conduta de vida. A obra de Max Weber na qual se debruçou a análise deste artigo foi "A Ética Protestante e o Espírito do Capitalismo".

\section{"Espírito" do capitalismo}

O que se deve entender por "espírito" do capitalismo? Qual é o melhor objeto utilizado a fim de designar significação a esse conceito? De acordo com Weber (2007, p. 41), o conceito deve ser entendido como um "um complexo de conexões que se dão na realidade histórica e que nós encadeamos conceitualmente em um todo, do ponto de vista de sua significação cultural”.

Ou seja, consiste em um tipo ideal (1992), recurso metodológico de caráter heurístico utilizado pelo pesquisador para investigar a realidade social, através da consideração das características gerais e amplas que caracterizam certo fato histórico (WEISS, 2014). O autor também afasta também qualquer pretensão ontológica de seu recurso metodológico, na medida em que não devemos "tentar enfiar a realidade em conceitos genéricos abstratos, mas antes procurar articulá-la em conexões concretas, sempre e inevitavelmente de colorido especificamente individual (2007, p. 42)". 
Tendo como referência um texto de Benjamin Franklin (1706-1709), cientista, calvinista e um dos fundadores da independência americana, Weber começa a delinear aquilo que compreende por "espírito" do capitalismo. No texto de Franklin - Almanaque do Pobre Ricardo (1739) - a ética está diretamente vinculada ao utilitarismo. É o que indica Weber:

No fundo, todas as advertências morais de Franklin são de cunho utilitário: a utilidade é útil porque traz crédito, e o mesmo que se diga da pontualidade, da presteza, da frugalidade também, e é por isso que são virtudes: donde se conclui, por exemplo, entre outras coisas, que se a aparência de honestidade faz a mesma coisa, é o quanto basta, e um excesso de virtude haveria de parecer, aos olhos de Franklin, um desperdício improdutivo condenável. (2007, p. 46)

Quer dizer, as virtudes humanas são condicionadas, em última instância, pelo utilitarismo, conforme depreende Weber dos sermões de Franklin ao apontar que "todas as virtudes, aliás, só são virtudes para Franklin na medida em que forem, inconcreto, úteis ao indivíduo (2007, p. 46)".

Ao seguir analisando as ideias de Franklin, Weber objetiva demonstrar a especial tendência dos dogmas protestantes em desenvolver o racionalismo econômico. O impulso para o ganho existiu muitos anos antes do desenvolvimento do próprio sistema econômico capitalista. No entanto, a ação visando ao lucro racionalmente calculado se desenvolveu primeiro em países com forte influência protestante, como Alemanha e Estados Unidos. Assim, o autor aponta um dos fundamentos principais que orientam essa ética:

[...] acima de tudo, este é o summum bonum dessa ética: ganhar dinheiro e sempre mais dinheiro, no mais rigoroso resguardo de todo gozo imediato do dinheiro ganho, algo tão completamente despido de todos os pontos de vista eudemonistas ou mesmo hedonistas e pensando tão exclusivamente como fim em si mesmo, que, em comparação com a 'felicidade' do indivíduo ou sua 'utilidade', aparece em todo caso como algo inteiramente transcendente e simplesmente irracional. (2007, p. 46).

A característica central dessa "ética social” apresenta, então, uma concepção invertida entre o ser humano e o lucro, na medida em que concebe o ganho como finalidade última da vida humana. No que concerne ao impulso desenfreado ao lucro, Weber defende que o mesmo já se manifestava em eras pré-capitalistas, períodos baseados ainda no que o autor chama de "tradicionalistas", não podendo, portanto, encaixar-se como uma das características do "espírito" do capitalismo. Mas em que sentido Weber entende o termo "pré-capitalista"? Segundo o autor $(2007$, p. 51), o termo deve ser entendido "no sentido de que a valorização 
racional do capital no quadro da empresa e a organização capitalista do trabalho ainda não haviam se tornado potencias dominantes na orientação da ação econômica".

Passemos, agora, às justificativas morais que legitimaram o "espírito" do capitalismo como um modo de ver portado por um grupo de pessoas através de sua concepção de profissão e conduta de vida.

\section{Profissão como vocação}

Se Weber considera que as condutas de vários agentes se orientam umas com relação a outras, é necessário que existam elementos que condicionem essas relações sociais. Em "A Ética Protestante e o Espírito do Capitalismo", residem nos grandes sistemas de valores - a saber, as religiões - as chaves-explicativas para uma civilização secular baseada na razão instrumental. E a ideia mais coerente de vocação profissional é encontrada nos textos teológicos de uma das vertentes do protestantismo: o puritanismo inglês.

A relação entre profissão e religião pode ser expressa pelo seguinte questionamento: em que sentido uma relação singular com o trabalho, condicionada por valores religiosos, teria contribuído para o fomento de características específicas do capitalismo no Ocidente? Mais especificamente, essa questão pode ser melhor discutida através do seguinte deslocamento disposicional: inclinação de ganhar o salário de costume (que cobre, via de regra, necessidades básicas) com um máximo de comodidade e um mínimo de esforço para a disposição de executar o trabalho como se fosse um fim absoluto em si mesmo: como uma "vocação", como um dever. Ou seja, trata-se do confronto que o "espírito" do capitalismo teve de se envolver com inclinações tradicionais de engajamento com o trabalho para, enfim, fazer emergir suas bases valorativas.

De acordo com Weber, a disposição tradicional de se envolver com o trabalho abarcou tanto operários como empresários. Sobre os primeiros sujeitos econômicos, Weber advoga que o ganho financeiro, tradicionalmente, sempre foi encarado como um meio de suprir necessidades materiais, não como uma finalidade última de vida. Ao comentar sobre atividades econômicas onde é imprescindível a introdução de técnicas voltadas à intensificação do trabalho, Weber cita o caso da agricultura, onde os ganhos oriundos da colheita são reféns da oscilação climática. Como forma de aproveitar ao máximo as boas condições climáticas, Weber lembra que empresários tendem a oferecer salários por tarefas aos seus operários, elevando a taxa de remuneração por tarefa mediante elevação do rendimento de trabalho. A resposta esperada por parte dos trabalhadores aos estímulos 
empresariais seria, normalmente, a intensificação do trabalho. Mas Weber sustenta que em muitos casos o que se verificou foi justamente o contrário - o arrefecimento da jornada de trabalho. Sobre a mentalidade de um operário tradicional típico, Weber afirma que "ganhar mais o atraía menos que o fato de trabalhar menos (2007, p. 53)”. Portanto, a disposição tradicional em relação ao trabalho era expressa na conformação com uma determinada condição social e com a inclinação de trabalhar apenas o necessário para conservá-la.

Com relação aos empresários, Weber advoga que tanto o impulso ao lucro como a sede de adquirir dinheiro são traços que já haviam se manifestado em eras pré-capitalistas. O ethos próprio do empresário tradicional, de acordo com Weber, era expresso pelas seguintes características: cadência dos negócios, montante de lucros pequeno, amena jornada de trabalho, modo tradicional de se conduzir os negócios e de se relacionar com os trabalhadores e com a freguesia e, por fim, maneira reativa de conquistar clientes e mercados. A respeito dessa conduta tradicional, Weber comenta sobre a vida de um empresário da indústria têxtil do século XIX, considerada, no ponto de vista do autor, "cômoda" para os padrões atuais da seguinte maneira:

\begin{abstract}
A visita pessoal à clientela era feita, se tanto, de quando em quando com longos intervalos, bastando de início a troca de correspondência e o envio de amostras, prática que se difundiu pouco a pouco e cada vez mais. O número de horas no escritório, modesto: talvez cinco ou seis horas por dia, por vezes muito menos, e na temporada, se temporada houvesse, mais; os ganhos, razoáveis, suficientes para levar uma vida decente e, em tempos de vacas gordas, fazer um pé-de-meia; no geral, um clima de grande cortesia entre os concorrentes graças a uma concordância relativamente grande quanto aos princípios básicos do negócio; generosa visita diária à taberna ou ao café para o trago do fim da tarde e o encontro com os amigos. Pacato andamento da vida, no geral. (2007, p. 59).
\end{abstract}

Embora com desdobramentos diferentes com relação às disposições dos operários, ambos os sujeitos econômicos convergem em um ponto fundamental: a orientação da ação econômica com base em uma "economia de satisfação das necessidades tradicionais (WEBER, 2007, p. 56)". Em suma, o tradicionalismo citado por Weber consiste na negação enfática por parte do ser humano em ganhar dinheiro como finalidade última de sua existência. Trata-se "simplesmente de viver, viver do modo como está habituado a viver e ganhar o necessário para tanto (WEBER, 2007, p. 53)".

Quanto ao sentimento da profissão como um dever, como uma "vocação" que exerce imperativos nos indivíduos, Weber aponta que ele opera com base em três critérios: o primeiro são critérios morais, o segundo é a importância social que os bens produzidos 
carregam à coletividade e, por fim, o terceiro é o de maior importância do ponto de vista prático - a capacidade de gerar lucro econômico privado.

Na perspectiva do puritanismo inglês, os prazeres terrestres pertencem à ordem do pecado. Assim, o critério moral está assentado na validade do trabalho como um meio ascético de preservação contra todas as tentações da vida impura. A perda de tempo é considerada o mais grave de todos os pecados: é justamente nos momentos de tempo ocioso que as pessoas encontram-se mais suscetíveis ao gozo dos prazeres carnais e, consequentemente, ao abandono a uma vida santa e pura. $\mathrm{O}$ descanso não pertencente ao plano terrestre: “o 'descanso eterno dos santos' está no Outro Mundo; na terra o ser humano tem mais é que buscar a certeza de seu estado de graça, 'levando a efeito, enquanto for de dia, as obras daquele que o enviou (WEBER, 2007, p. 143)".

A ideia de vocação, de um dever que se exerce através do trabalho aos indivíduos, está amarrada a um princípio puritano de que o indivíduo deve trabalhar asceticamente para construir, na terra, o reino de Deus. Nesse sentido, o tempo é tão precioso porque "cada hora perdida é trabalho subtraído ao serviço da glória de Deus (WEBER, 2007, p. 144)”. Para não se desvirtuar do caminho sagrado, a receita é clara: "contra todas as tentações sexuais, do mesmo modo que contra as dúvidas religiosas e os escrúpulos torturantes, além de uma dieta sóbria à base de refeições vegetarianas e banhos frios, receita-se: 'trabalhe duro na tua profissão"". Como se depreende das palavras citadas de Weber, além da necessidade de trabalhar asceticamente para ser operário da glória de Deus, o trabalho realizado pelos indivíduos também deve estar inserido em uma determinada profissão. Fora dela, os empreendimentos humanos são ocasionais e precários, faltando-lhes um caráter mais metódico. O que é recomendado pela ética protestante, então, não é o trabalho em si, mas um trabalho profissional racional que opere metodicamente. Sem esse caráter metódico da profissão, o trabalho é desorganizado e, segundo os princípios da ética protestante, o indivíduo gasta mais tempo "vadiando que trabalhando (WEBER, 2007, 147)".

Além das preocupações sagradas, como a perda de tempo e as possíveis tentações advindas do tempo ocioso, a racionalização do trabalho dentro de uma profissão bem delimitada se aproxima, ainda, de princípios bastante pragmáticos próprios da literatura profana. Dessa forma, a famosa tese de Adam Smith sobre a relação entre a divisão do trabalho e o crescimento econômico das nações é, em boa medida, também compartilhada pela ética protestante. Trata-se do segundo critério da profissão como uma vocação: a importância social que os bens produzidos pelo trabalho carregam à coletividade. Isso é expresso nas palavras de Weber da seguinte forma: "a especialização das profissões, por 
facultar ao trabalho uma competência, leva ao incremento quantitativo e qualitativo do rendimento de trabalho e serve, portanto, ao bem comum, que é idêntico ao bem do maior número possível (WEBER, 2007, p. 146)”. Ora, essa ideia da necessidade de substituição do trabalho enquanto uma produção individual para uma profissão especializada como uma condição para o incremento do trabalho converge com a afirmação de Adam Smith (1996, vol. 1) de que "a divisão do trabalho, na medida em que pode ser introduzida, gera, em cada ofício, um aumento proporcional das forças produtivas do trabalho (p. 66)". Isso é devido ao fato de que "a divisão do trabalho, reduzindo a atividade de cada pessoa a alguma operação simples e fazendo dela o único emprego de sua vida, necessariamente aumenta muito a destreza do operário (p. 68)." Além de uma maior destreza, a divisão do trabalho em profissões especializadas poupa aquele tempo que, em um trabalho não especializado, seria perdido ao se passar de uma atividade a outra.

Ao fim e ao cabo, o último critério refere-se à capacidade de uma dada profissão gerar lucro econômico privado. Essa legitimação da capacidade lucrativa acontece, no entanto, com algumas ressalvas. A riqueza, caso utilizada como um meio de descanso sobre bens materiais conquistados, é um grave perigo e, portanto, moralmente reprovável. Nas palavras de Weber (2007) "a riqueza é reprovável precisamente e somente como tentação de abandonar-se ao ócio, à preguiça e ao pecaminoso gozo da vida, e ambição de riqueza somente o é quando o que se pretende é poder viver mais tarde sem preocupação e prazerosamente (p. 148)". Por outro lado, se a riqueza é resultado do desempenho do dever vocacional de um indivíduo, ela não só é moralmente aceita como é também um mandamento divino. $\mathrm{O}$ aumento da riqueza só é justificado com um fim em si mesmo, como um sinal de virtude, de honestidade de caráter e de eficiência em uma vocação.

Além da eficiência em uma vocação profissional, outro aspecto que deve ser articulado à legitimação da riqueza é o de "chamamento". Na concepção do puritanismo a respeito do período de pós-morte, o decreto divino da salvação ou da condenação já está predestinado. Condenados ou não, os indivíduos se vêm obrigados a conviver com as agruras da incerteza. Uma forma de lidar com isso foi o afinco ao trabalho em uma profissão. Mas eram necessários ainda sinais de escolha, algum indício de "chamamento" divino que amenizasse a dúvida religiosa. E é através desse dilema acerca do decreto divino sobre a salvação ou não que a riqueza é legitimada: sendo o resultado do trabalho incansável em uma profissão, o lucro econômico é uma benção, um sinal de salvação divina. Nas palavras de Weber: 
Pois se esse Deus, que o puritano vê operando em todas as circunstâncias da vida, indica a um dos seus uma oportunidade de lucro, é que ele tem lá suas intenções ao fazer isso. Logo, o cristão de fé tem que seguir esse chamado e aproveitar a oportunidade. "Se Deus vos indica um caminho no qual, sem dano para vossa ordem ou para outrem, possais ganhar nos limites da lei mais do que num outro caminho, e vós o rejeitais e seguis o caminho que vai trazer ganho menor, então estareis obstando um dos fins do vosso chamamento, estareis vos recusando a ser o administrador de Deus e a receber os seus dons para poderdes empregá-los para Ele se Ele assim o exigir. Com certeza não para fins concupiscência da carne e do pecado, mas sim para Deus, é permitido trabalhar para ficar rico". (2007, p. 148).

Na citação acima, fica elucidado, então, que o lucro econômico é um sinal da escolha divina, um chamamento para que o sujeito escolhido utilize seus dons para ser o operante de Deus no plano terrestre. Se não utilizado para fins pecaminosos e gerado dentro dos limites estabelecidos pela lei, o indivíduo não só pode como também deve aproveitar a oportunidade de lucrar.

$\mathrm{Na}$ análise de Weber, a combinação desses três critérios supracitados da noção de profissão enquanto uma "vocação" apresentou efeitos significativos para o desenvolvimento do capitalismo. Resumindo-a, ela enfaticamente reprova o descanso sobre posses e o consumo, especialmente o consumo de luxo, ao mesmo tempo em que não só liberaliza a obtenção de lucro como também o justifica moralmente como um sinal de graça divino. Em termos práticos, a amálgama desses critérios acabou por implicar no "acúmulo de capital mediante coerção ascética da poupança. Os obstáculos que agora se colocavam contra empregar em consumo o ganho obtido acabaram por favorecer seu emprego produtivo: o investimento de capital (WEBER, 2007, p. 157)”. Com isso, emergem as bases para a formação de um novo ethos profissional. Trata-se da passagem do sujeito econômico tradicional para o inovador, que afeta tanto empresários como operários. Esse novo tipo de sujeito econômico é descrito por Weber da seguinte maneira:

Com a consciência de estar na plena graça de Deus e ser por ele visivelmente abençoado, o empresário burguês, com a condição de manter-se dentro dos limites da correção formal, de ter sua conduta moral irrepreensível e de não fazer sua riqueza um uso escandaloso, podia perseguir os seus interesses de lucro e devia fazê-lo. O poder da ascese religiosa, além disso, punha à sua disposição trabalhadores eficientes e aferrados ao trabalho como se finalidade de sua vida, querida por Deus. E ainda por cima dava aos trabalhadores a reconfortante certeza de que a repartição desigual dos bens deste mundo era obra toda especial da divina Providência, que, com essas diferenças, do mesmo modo que com a graça restrita - não universalista -, visava a fins por nós desconhecidos. (2007, p. 161). 
Ademais, a ética protestante defendia que o trabalho profissional leal, mesmo que mal remunerado, representava uma conduta positiva perante a vontade divina e, portanto, ao bem comum. Ora, essa justificação inclusive do trabalho mal pago forma o alicerce à produtividade baseada na teoria dos baixos salários. Considerando a existência de desejos ilimitados por parte dos indivíduos e a escassez de recursos disponíveis no mercado, essa ética conseguiu conformar distintas aspirações e impulsos na concepção de profissão como "vocação", formando uma sinergia imprescindível ao desenvolvimento econômico capitalista.

\section{Regimento ascético da conduta de vida}

O principal traço característico do regimento ascético da conduta de vida puritana consiste na reprovação do gozo descontraído da vida e do que ela tem a oferecer em alegria. Trata-se, portanto, de uma negação veemente de todos os pontos de vista hedonistas acerca da existência humana. No entanto, na medida em que cresce o número de posses, aumentam também as "tentações" da riqueza e das posses. Analisemos, então, como Weber explica o desafio da regulamentação ascética dos costumes frente à vontade de viver de pequenoburgueses enriquecidos.

Um dos grandes embates travados pela ascese puritana foi contra a contemplação estética e esportiva de bens culturais. Nas palavras de Weber (2007, p. 154-155) “[...] a liceidade da alegria proporcionada por bens culturais puramente destinados à fruição estética ou esportiva esbarrava em um limite: ela não devia custar nada". Quer dizer: se no plano terrestre os indivíduos devem trabalhar arduamente dentro de uma profissão com vistas a serem os operantes da glória divina, é equivocado gastar tempo contemplando um bem que não tem validade para Deus, e sim para a fruição pessoal. Ademais, a riqueza é, em última instância, um agraciamento divino. Logo, aquele contemplado com a riqueza é, antes de tudo, um administrador dos bens de Deus e tem não só a incumbência, mas o dever de empregá-la sempre em outros bens e processos úteis, com a finalidade de multiplicá-la e canalizá-la ao bem comum. Sobre esse dever, Weber escreve o seguinte:

A ideia da obrigação do ser humano para com a propriedade que lhe foi confiada, à qual se sujeita como prestimoso administrador ou mesmo como uma "máquina de fazer dinheiro", estende-se por sobre a vida feito uma crosta de gelo. Quanto mais posses, tanto mais cresce - se a disposição ascética resistir a essa prova - o peso de sentimento de responsabilidade não só de conservá-la na íntegra, mas ainda de multiplicá-la para a glória de Deus através do trabalho sem descanso (2007, p. 155). 
Ora, é sabido que bens culturais não têm, necessariamente, uma finalidade utilitária. Também não têm, necessariamente, a obrigação de operarem como uma "máquina de fazer dinheiro". Dessa forma, torna-se patente a tensão entre ascese puritana e bens culturais, entre o dever de conservar uma vida rigidamente regrada e a atração por atividades não pragmáticas, voltadas ao deleite.

Assim, a figura ao mesmo tempo simples e sóbria do novo burguês (o empresário inovador ou o "empresário novo estilo") imbuído dos valores puritanos se chocava com tudo aquilo que não fosse utilitário e pragmático. Nesse sentido, a prática do esporte era moralmente reprovável pela ascese. Contudo, Weber pondera que essa reprovação não se dava simplesmente por uma questão de princípio do esporte: se atendesse a algum fim racional - como, por exemplo, a restauração física, tão cara ao labor produtivo -, o esporte poderia ser aproveitado como uma atividade válida. De maneira diversa a algum fim racional, contudo, era condenável:

[...] já como simples meio de descontrair e descarregar impulsos indisciplinados, aí se tornava suspeito e, evidentemente, na medida em que fosse praticado por puro deleite ou despertasse fissura agonística, instintos brutais ou o prazer irracional de apostar, é evidente que o esporte se tornava pura e simplesmente condenável. O gozo instintivo da vida que em igual medida afasta do trabalho profissional e da devoção era, exatamente enquanto tal, o inimigo da ascese racional, quer se apresentasse na forma de esporte "grã-fino" ou, da parte do homem comum, como frequência a salões de bailes e tabernas (WEBER, 2007, p. 152).

Além dos bens culturais de fruição esportiva, a ascese puritana também reprovava e hostilizava os bens culturais de fruição estética. Apesar disso, Weber pondera que não se pode afirmar que os ideais puritanos de vida estivessem ligados a um desprezo obscurantista da cultura. Nessa direção, o sociólogo alemão lembra que pelo menos no campo científico houve uma presença significa de representantes do movimento puritano. Cenário completamente diferente é quando se dirige o foco de análise ao terreno da literatura não científica e, sobretudo, ao campo das belas artes voltadas à expressão da subjetividade. Sobre a resistência às dimensões menos objetivas da cultura, Weber (2007, p. 153) escreve da seguinte maneira:

Aqui, sem dúvida, a ascese caiu feito geada na vida da "radiante Inglaterra de outrora". E não só as festas profanas foram afetadas. O ódio enfurecido dos puritanos contra tudo que cheirasse superstição, contra todas as reminiscências da dispensação mágica ou hierúrgica da graça, perseguiu a festa cristã do Natal quanto à árvore de maio, além da prática de uma arte sacra naïf. 
Além das belas artes e da literatura não-científica, a ascese puritana também condenava o teatro e as vestimentas não inseridas em um padrão homogêneo. Conceitos como os de conversa mole, ostentação vã e superficialidades eram as designações usadas para se referir às expressões artísticas. Eram tratadas, em síntese, "como um comportamento irracional, sem finalidade e, por conseguinte, não ascético, e que ainda por cima não serviam à glória de Deus, mas à do homem [...] (WEBER, 2007, p. 154)". Quanto à padronização exigida pela ascese do traje vestido, que caminhava lado a lado à massificação registrada na produção, Weber explica que seu fundamento estava articulado à rejeição da divinização da criatura.

Por outro lado, se houve registro histórico de países com influência dos ideais puritanos e que mesmo assim conseguiram desenvolver expressões artísticas significativas, Weber também lembra que a regulamentação dos costumes não ocorria de maneira exclusiva, tendo de competir com a corte e o estamento de regentes, além da "própria vontade de viver de pequeno-burgueses enriquecidos depois que a breve dominação da teocracia calvinista se diluiu numa insípida igreja estatal, tendo com isso o calvinismo perceptivelmente perdido em força de atração ascética (2007, p. 153)".

A respeito da dificuldade de regulamentar os costumes, o problema pode ser mais especificamente posto da seguinte forma: na medida em que aumentavam as acumulações de riquezas, aumentavam as tentações ao enobrecimento das fortunas e as fragilidades da disciplina religiosa. Assim, as regras religiosas travaram uma luta constante contra o efeito secularizante do aumento da riqueza. Weber observa que, paulatinamente, o aumento da riqueza foi seguido de um decréscimo da essência religiosa, trazendo, na sua esteira, problemas como o orgulho, a concupiscência da carne, a arrogância, a ira, etc. Sobre desse arrefecimento dos valores religiosos como efeito colateral secularizante da riqueza, Weber escreve o seguinte:

Pois bem: esses ideais de vida puritanos fraquejaram diante da duríssima prova de resistência a que os submeteram as "tentações" da riqueza, suas velhas conhecidas. É muito frequente encontrarmos os mais genuínos adeptos do espírito puritano nas fileiras das camadas de pequeno-burgueses em vias de ascensão, dos farmers e dos proprietários felizardos, quase sempre prontos, mesmo entre os quakers, a renegar os velhos ideais. Sim, este foi, afinal de contas, o mesmo destino a que sucumbiu a precursora da ascese intramundana, a ascese monacal da Idade Média: se aqui, na sede de uma vida rigidamente regrada e de consumo freado, a direção racional da economia produziu o máximo de seus efeitos, aconteceu que, uma vez acumulada à fortuna, ou se cedeu diretamente ao enobrecimento - e isso ocorria na época anterior ao cisma - ou, quando menos, a disciplina 
monástica ficava a ponto de se arrebentar, e aí acabava tendo que intervir uma daquelas incontáveis "reformas" (2007, p. 159).

Por outro lado, Weber também lembra que a educação para a ascese somente conseguiu, com efeito, desenvolver sua eficácia econômica com maior regularidade "quando o ápice do entusiasmo puramente religioso já havia sido ultrapassado, quando a tensão da busca por Deus começou pouco a pouco a se resolver em sóbria virtude profissional [...] e deu lugar a intramundanidade utilitária [...] $(2007,160)$ ”. Ou seja, a sinergia entre religião e economia foi canalizada somente quando angústia causada pela dúvida religiosa foi paulatinamente sendo amenizada pela ética do trabalho como "vocação" e seus preceitos utilitários; quando, enfim, a ética sagrada foi sendo resignificada pela ética utilitária profana. Essa passagem à intramundanidade utilitária é descrita pelo autor da seguinte forma "quando em seguida tornou-se dominante o princípio 'to make the best of both worlds', era fatal [...] que a boa consciência fosse simplesmente posta no rol dos meios para uma vida burguesa confortável [...] (2007, p. 161)".

Finalmente, Weber conclui que o legado deixado pela época religiosamente vivaz do século XVII à sua herdeira utilitária foi uma consciência imensamente boa no que concerne ao ganho monetário, ao lucro econômico privado, desde que esse ocorresse dentro dos limites estabelecidos pelas leis. Foi, enfim, erigir as bases de um repertório moral para a constituição de um novo sujeito econômico, um profissional com uma ética especificamente burguesa.

\section{Considerações finais}

O objetivo que norteou este artigo foi analisar, a partir da obra "A Ética Protestante e o Espírito do Capitalismo", de Max Weber, como modalidades de concepção de profíssão e de condutas de vida foram adaptadas à peculiaridade do capitalismo ocidental moderno, formando um novo ethos profissional.

Uma das ideias-força da obra é a de que o "espírito" do capitalismo não pode ser explicado pelo interesse individual de indivíduos atomizados, orientados por considerações de preço e visando à maximização de lucro. Isso porque a própria a racionalidade instrumental não é capaz de estruturar a ação dos sujeitos tão eficaz e sistematicamente quanto uma racionalidade imbuída de valores. Assim, a obra dirige sua atenção aos círculos de ideias e valores que produziram os efeitos psicológicos necessários para a internalização de determinadas disposições acerca do trabalho e da conduta de vida, imprescindíveis à formação do "espírito" do capitalismo. Nesse sentido, Weber recorre a textos teológicos que nasceram 
da práxis pastoral da cura de almas, mais especialmente aos pregadores da ética puritana, para compreender os grandes sistemas de valores do século XVII.

No tocante à concepção de profissão, o processo ocorre através da ideia de profissão como "vocação", ou seja, como um dever que cada indivíduo sente de trabalhar arduamente a fim de ser o operante da glória de Deus no plano terrestre. Conforme Weber, ela opera com base em três critérios fundamentais: o primeiro é de cunho moral, enfatizando o trabalho profissional como meio ascético de preservação contra todos os pecados e tentações; já o segundo é de cunho social, sublinhando a importância qualitativa e quantitativa dos bens produzidos pelo trabalho profissional ao bem comum; o terceiro, por fim, é o mais importante em termos práticos e é, pois, de cunho pragmático, destacando importância do lucro econômico privado como um sinal de benção divina.

Já quanto à conduta de vida, o processo ocorre pela reprovação ao gozo descontraído da vida. Dessa forma, a legalidade proporcionada por bens culturais destinados ao desfruto puramente estético ou esportivo esbarrava em um limite: ela não devia custar nada. Como os indivíduos possuem o dever de serem os operantes da glória de Deus na Terra, é reprovável gastarem seu tempo com atividades voltadas ao interesse próprio, e não de Deus. Ademais, bens culturais não seguem, necessariamente, a lógica do utilitarismo tão cara à ascese intramundana, sendo, então, enfaticamente reprovados.

Além de incentivar o trabalho profissional incansável, a ética protestante impele o crente a desconfiar dos bens desse mundo, fazendo-o adotar um comportamento ascético. Ora, trabalhar racionalmente com vistas ao lucro, e não gastá-lo, reinvestindo-o incessantemente na produção, é uma das condições essenciais para o funcionamento do capitalismo. Esses foram, então, os fatores de ajustamento do "espírito" do capitalismo ao sistema econômico capitalista moderno.

AGRADECIMENTOS: CAPES

\section{REFERÊNCIAS}

SMITH, Adam. A Riqueza das Nações. São Paulo: Editora Nova Cultural, 1996, Vol.1.

WEBER, Max. A Ética Protestante e o Espírito do Capitalismo. Edição especial revisada por Antônio Flávio Peirucci. São Paulo: Companhia das Letras, 2007.

WEBER, Max. A Gênese do Capitalismo Moderno. São Paulo: Ática, 2006. 
WEISS, Raquel. Max Weber e o problema dos valores: as justificativas para a neutralidade axiológica. Revista de Sociologia e Política, Curitiba, v. 22, n. 49, p. 113-137, mar., 2014. Como referenciar este artigo

MELLO, Pedro D. As justificativas morais do "espírito" do capitalismo a partir de concepção de profissão e regimento ascético da conduta de vida. Rev. Sem Aspas, Araraquara, v. 6, n. 2, p. 146-160, jul./dez., 2017. E-ISSN: 2358-4238.

Submetido em: 01/12/2017

Aprovado final em: 07/03/2018 